\title{
Incomplete tubular duplication of the esophagus becoming symptomatic in adulthood
}

Esophagogastroduodenoscopy was performed in a 48-year-old Caucasian male suffering from progressive dysphagia for 2 years. A stenosis of unknown origin was found at $25 \mathrm{~cm}$ from the incisors, which could not be passed by a conventional endoscope $(8.8 \mathrm{~mm})$ ( $\bullet$ Fig. 1). The stenosis was characterized by two lumina separated by a bridge of intact mucosa. Computed tomography scans showed extensive thickening of the esophageal wall, probably due to scarring, with formation of a septum in the esophageal lumen ( $\bullet$ Fig. 2). Using a pediatric endoscope $(5.9 \mathrm{~mm}$ ) the proximal stenosis could be passed. At $38 \mathrm{~cm}$, a septum of intact mucosa was found similar to that in the proximal esophagus. Again, two lumina could be observed; however, only the larger lumen could be intubated endoscopically ( $\bullet$ Video 1 ). A guide wire showed communication of the two esophageal ducts ( Fig. 3). Miniprobe endosonography revealed normal muscular layers within the esophageal wall as well as within the septum ( $\bullet$ Fig. 4). Kinematography showed a long-segment stenosis of the upper esophagus and an additional filiform, blind-ending lumen ventral to the esophageal main lumen ( Video 2). Incomplete tubular duplication of the esophagus was diagnosed.

Duplication of the esophagus is a rare congenital malformation caused by an error in early embryogenesis, with an incidence of about 1 in 8200 [1]. The cystic form of esophageal duplication is more commonly observed whereas the tubular type seems to be extremely rare $(5 \%-10 \%)$ [2]. Most patients $(70 \%-90 \%)$ who suffer from esophageal duplication become symptomatic in childhood and are diagnosed before 2 years of age. Only a few case reports exist of tubular esophageal duplication being discovered incidentally in adulthood [3-5]. According to the very limited literature, surgery is the first-line treatment of tubular esophageal duplication. In our case, however, the patient refused surgery. Dilation therapy and proton pump inhibitor medication led to clinical improvement with satisfactory relief of the patient's complaints.

Endoscopy_UCTN_Code_CCL_1AB_2AC_3AH

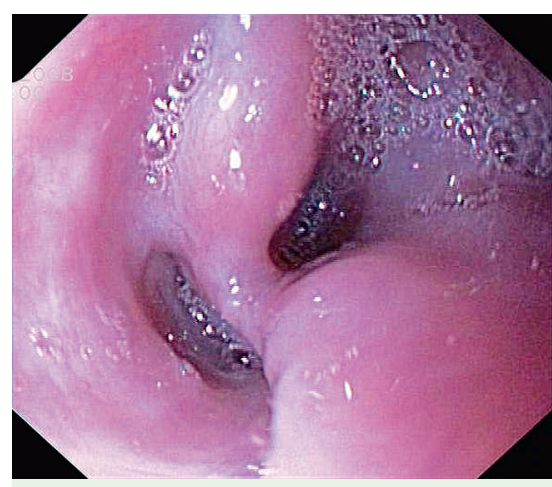

Fig. 1 Upper gastrointestinal endoscopy revealed a stenosis at $25 \mathrm{~cm}$ with proximal dilation and diverticulum-like lesions.

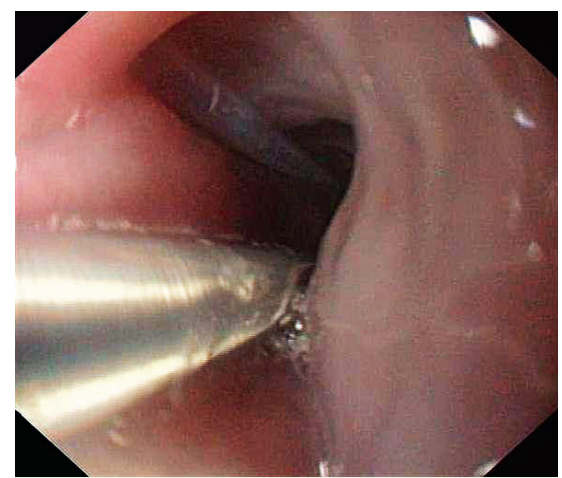

Fig. 3 Communication of the two esophageal lumina at $35 \mathrm{~cm}$.

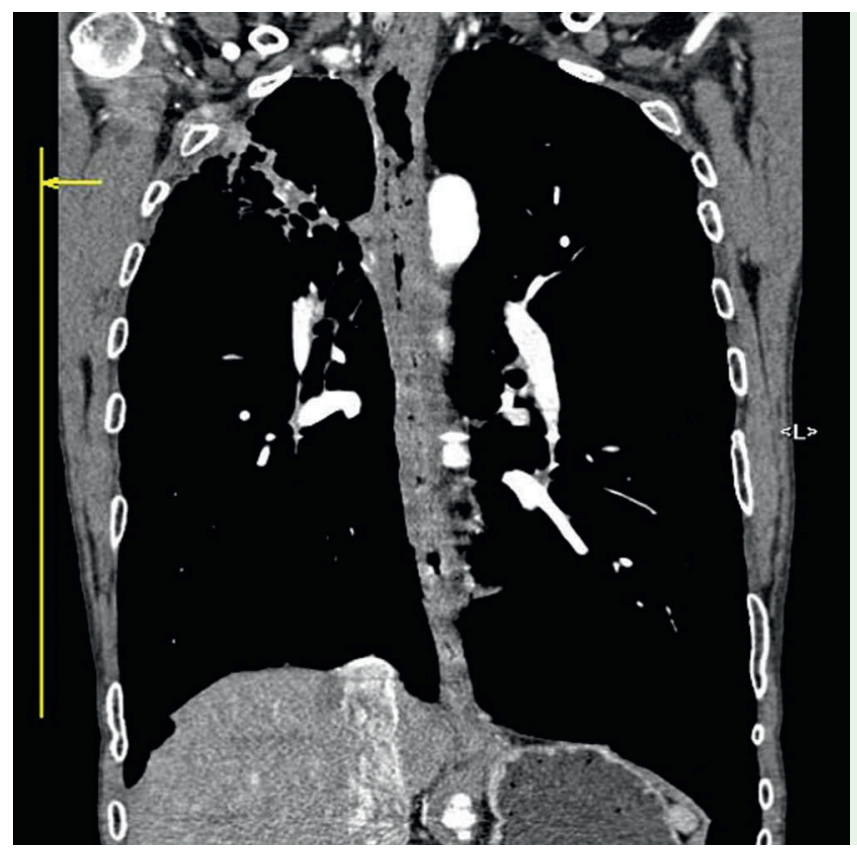

Fig. 2 Computed tomography scan showed extensive thickening of the esophageal wall and a septum in the esophageal lumen.

\section{Video 1}

Upper gastrointestinal endoscopy showed a septum of intact mucosa at $38 \mathrm{~cm}$ and $25 \mathrm{~cm}$ from the incisors forming two esophageal lumina.

\section{Video 2}

Kinematography revealed a long-segment stenosis of the upper esophagus with no regular esophageal contractions. An additional filiform, blind-ending lumen was contrasted ventral to the esophageal main lumen.
P. Lenz ${ }^{1}$, J. Wessling ${ }^{2}$, D. Foell ${ }^{3}$, D. Bettenworth ${ }^{1}$, T. Nowacki ${ }^{1}$,

H. Ullerich ${ }^{1}$, W. Domschke ${ }^{1}$, D. Domagk ${ }^{1}$ Department of Medicine B, University of Muenster, Muenster, Germany

2 Department of Clinical Radiology, University of Muenster, Muenster, Germany Department of Paediatrics, University of Muenster, Muenster, Germany 


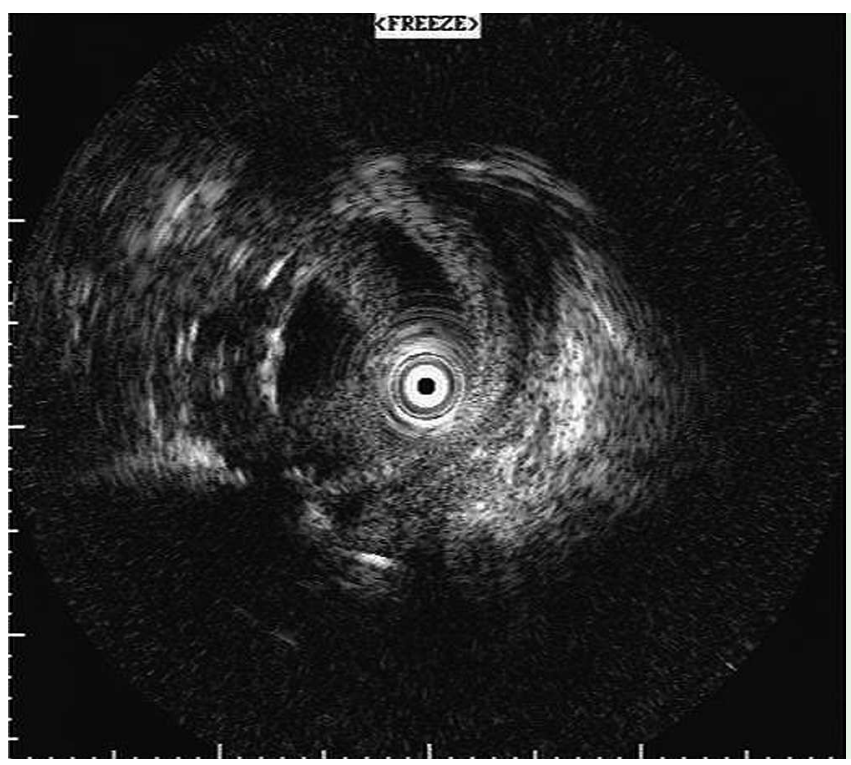

Fig. 4 Endosonographically physiological muscular layers of the esophageal wall with no hint of malignancy and normal muscular layers within the septum.

\section{References}

1 Estefan VD, Reibscheid S, Colleoni R et al. Surgical images: soft tissue. Tubular duplication of the esophagus. Can J Surg 2008; 51: 205-206

2 Cheynel N, Rat P, Couailler JF et al. Tubular duplication of the esophagus. Contribution of magnetic resonance imaging in anatomical analysis before surgery. Surg Radiol Anat 2000; 22: 289-291
3 Cantallops JG, Adrover AO, Fernandez JM et al. Incomplete duplication of the esophagus: one case. Endoscopy 1981; 13: 46- 48

4 Jobe BA, Baumann HW, Domreis JS et al. Communicating esophageal duplication with Barrett's esophagus and high-grade dysplasia. Surgery 2002; 132: $112-114$

5 Mehta R, Unnikrishnan G, Sudheer OV et al. Incidental detection of tubular esophageal duplication in gastric cardia malignancy. Indian J Gastroenterol 2004; 23: 192
Bibliography

DOI $10.1055 / s-0029-1214631$

Endoscopy 2009; 41: E114-E115

(c) Georg Thieme Verlag KG Stuttgart · New York . ISSN 0013-726X

Corresponding author

\section{P. Lenz, MD}

Department of Medicine B

University of Muenster

Albert-Schweitzer-Str. 33

D-48149 Muenster

Germany

Fax: +49-251-8347570

lenz.philipp@ukmuenster.de 